\title{
Incidence and mortality rates of selected infection-related cancers in Puerto Rico and in the United States
}

\author{
Ana P Ortiz ${ }^{* 1,2}$, Marievelisse Soto-Salgado33, William A Calo³, Guillermo Tortolero-Luna', Cynthia M Pérez², \\ Carlos J Romero ${ }^{4}$, Javier Pérez ${ }^{5}$, Nayda Figueroa-Vallés 1,5 and Erick Suárez ${ }^{2}$
}

\begin{abstract}
Background: In 2002, 17.8\% of the global cancer burden was attributable to infections. This study assessed the agestandardized incidence and mortality rates of stomach, liver, and cervical cancer in Puerto Rico (PR) for the period 19922003 and compared them to those of Hispanics (USH), non-Hispanic Whites (NHW), and non-Hispanic Blacks (NHB) in the United States (US).

Methods: Age-standardized rates [ASR(World)] were calculated based on cancer incidence and mortality data from the PR Cancer Central Registry and SEER, using the direct method and the world population as the standard. Annual percent changes (APC) were calculated using the Poisson regression model from 1992-2003.

Results: The incidence and mortality rates from stomach, liver and cervical cancer were lower in NHW than PR; with the exception of mortality from cervical cancer which was similar in both populations. Meanwhile, the incidence rates of stomach, liver and cervical cancers were similar between NHB and PR; except for NHB women who had a lower incidence rate of liver cancer than women in PR. NHB had a lower mortality from liver cancer than persons in PR, and similar mortality from stomach cancer.
\end{abstract}

Conclusions: The burden of liver, stomach, and cervical cancer in PR compares to that of USH and NHB and continues to be a public health priority. Public health efforts are necessary to further decrease the burden of cancers associated to infections in these groups, the largest minority population groups in the US. Future studies need to identify factors that may prevent infections with cancer-related agents in these populations. Strategies to increase the use of preventive strategies, such as vaccination and screening, among minority populations should also be developed.

\section{Background}

Infection with several viruses and bacteria has been associated to the development of various cancer types [1]. Nearly $17.8 \%$ of the global cancer burden is attributable to infectious agents [2], with a higher percentage in developing countries $(26.3 \%)$ than in developed countries (7.7\%) [3]. The principal infectious agents associated with cancer morbidity worldwide are Helicobacter pylori $(\mathrm{H}$. pylori) (5.5\% of all cancers), human papilloma viruses (HPV) (5.2\% of all cancers), and hepatitis B (HBV) and hepatitis $\mathrm{C}$ viruses $(\mathrm{HCV})$ (4.9\% of all cancers); these

* Correspondence: ana.ortiz7@upr.edu

${ }^{1}$ Cancer Control and Population Sciences Program, University of Puerto Rico Comprehensive Cancer Center, San Juan, Puerto Rico

Full list of author information is available at the end of the article agents account for $87.6 \%$ of the total cancer burden associated to infections [2]. More specifically, between 74\%$78 \%$ of all stomach cancers worldwide have been attributed to infection with $H$. pylori, $85.4 \%$ of hepatocellular carcinoma is attributable to HBV (54.4\%) or HCV (31.0\%) infection [3], while persistent infection with certain types of HPV has been established as a necessary cause for cervical cancer, accounting for $100 \%$ of these tumors [2]. Moreover, HPV infection has been associated to cancer of the vulva, vagina, penis, anus, oral cavity and oropharynx [3]. Among other cancer types, bladder and nasopharyngeal cancer, as well as various types of lymphomas and sarcomas, have also been associated to other infectious agents such as Schistosoma haematobium, Epstein-Barr virus, $\mathrm{HCV}, \mathrm{H}$. Pylori, human T-cell leukemia virus type 1

() 2010 Ortiz et al; licensee BioMed Central Ltd. This is an Open Access article distributed under the terms of the Creative Commons BH. Central Attribution License (http://creativecommons.org/licenses/by/2.0), which permits unrestricted use, distribution, and reproduction in any medium, provided the original work is properly cited. 
(HTLV-1), and human herpes virus 8 (HHS-8) [1,3-5]. Nonetheless, the percent of all cancers worldwide associated to these previously mentioned infections is less than $3 \%$ [3].

Worldwide, among infection-related cancers, stomach, liver, and cervix uteri cancers not only account for the vast majority of the total cancer burden associated to infections $[3,6]$, but they also have the highest incidence figures [1]. Although the incidence of total cancer in Puerto Rico (PR) is lower than that of the United States (US), the incidence from infection-related cancers such as stomach, liver and cervical cancer is higher in the island than in the US, particularly among non-Hispanic Whites (NHW). Contrary to the US, these cancer types also rank among the leading cancer sites in incidence and mortality in PR [7-12]. This pattern is similar to patterns observed among Hispanics in the US (USH) who show lower incidence and mortality rates from total cancer than NHW for the most frequent cancer types, although they experience a higher incidence of cancers related to infectious agents [13-15], similar to that of their countries of origin [16].

Information on the current burden of infection-related cancers in PR and how it compares with other US racial/ ethnic groups is limited because these comparisons have mainly focused on USH, NHW and non-Hispanic Blacks (NHB) $[14,15]$. Understanding patterns of cancer incidence in diverse racial/ethnic groups is essential to further understand risk factors for disease occurrence in specific populations and to direct appropriate cancer prevention and control efforts for specific population subgroups. Thus, this study aimed to assess the age-standardized incidence and mortality rates of stomach, liver and cervical cancer in PR and compared them to those of USH, NHW, and NHB in the US for the period 19922003.

\section{Methods}

Data sources

Incident cases and deaths for stomach, liver and cervical cancer for all racial/ethnic groups were obtained from the PR Central Cancer Registry (PRCCR) $[17,18]$ and the Surveillance, Epidemiology and End Results Program (SEER) $[19,20]$, respectively. The SEER program is a national cancer surveillance database that collects and reports incidence and survival data from a sample of the US population. The PRCCR is the fourth oldest populationbased cancer registry in the world [21] and collects information on cancer in PR since 1951. The PRCCR is part of the National Program of Cancer Registries (NPCR) administered by the Centers of Disease Control and Prevention (CDC). The PRCCR uses the coding standards of the SEER and of the North American Association of Central Cancer Registries (NAACCR); thus, the registry is fully comparable with SEER data. In the year 2003, a CDC audit concluded that $95.3 \%$ of all cancer cases diagnosed or treated in hospital facilities in PR were appropriately reported to the PRCCR; a result comparable to the US median (95\%) [22]. The third revision of the International Classification of Diseases for Oncology (ICD-O-3) was used to select all cases diagnosed from stomach, liver and cervical cancer between 2001 and 2003. Cases from 1992 to 2000 , which were originally reported using ICD-O-2, were converted to ICD-O-3. The specific codes for the types of cancer studied were: cervical cancer (C53.0C53.9), cancer of the liver and intraepithelial bile duct (C22.0-C22.1) and stomach cancer (C16.0-C16.9). Cancer mortality data for PR and the US (NHW, NHB, USH) was obtained, respectively, from the PRCCR as reported by death certificates enacted by vital statistics from the Puerto Rico Department of Health and from the SEER program as reported by the National Center for Health Statistics (NCHS). Causes of death were coded and classified according to the tenth edition International Classification of Diseases (ICD-10). Mortality codes for the specific types of cancer included: cervical cancer (ICD-9: 180.0-180.9, ICD-10: C53), cancer of the liver and intraepithelial bile duct (ICD-9:155.0-155.2, ICD-10:C22.0, C22.0-C22.4, C22.7, C22.9) and stomach cancer (ICD9:151.0-151.9, ICD-10:C16).

\section{Statistical Analysis}

For each racial/ethnic group, annual age-standardized incidence and mortality rates [ASR(World)] (per 100,000) of stomach, liver and cervical cancer for 1992-2003 were calculated, using the direct method (mortality rates were based on underling cause of death) and the world population as the standard [23]. To assess the trends in risk for specific sites, the annual ASR(World) were calculated by sex, as follows: $\operatorname{ASR}(\text { World })_{i}^{k}=\sum_{j=1}^{18} w_{j} \frac{d_{i j}^{k}}{n_{i j}^{k}}$ where $\mathrm{w}_{\mathrm{j}}$ is the proportion of persons in the $j$-th age group of the standard population, $\mathrm{d}_{\mathrm{ij}}$ is the number of cases (new cases or deaths) in the $j$-th age group for the $i$-th ethnic group in the $k$-th year, and $\mathrm{n}_{\mathrm{ij}}$ is the population in the $j$-th age group for the $i$-th ethnic group in the $k$-th year. The annual percent change (APC) of the ASR(World) was estimated using the joinpoint regression model [24]. The Joinpoint Regression Program version 3.3 [25] was used for the APC estimation using the following parameters: 1 ) 
logarithmic transformation of the rate, 2) zero joinpoint model, 3) Poisson model using rate, 4) uncorrelated error model, and 5) Hudson's method. To assess differences in the incidence and mortality rates of stomach, liver and cervical cancer between PR as compared to the other racial/ethnic groups, the ASR(World) were grouped from 1999 to 2003 (averaged over the 5-year period). Then, the standardized incidence ratio (SIR) and the standardized mortality ratio (SMR) were estimated with 95\% confidence intervals [26], to compare the racial/ethnic risk with PR as the reference group. We also compared sex differences in each racial/ethnic groups, with females as the reference group, in the occurrence of stomach and liver cancer. The STATA System release 10.0 (STATA Corp, College Station, TX, USA) was used for the statistical analysis.

\section{Results}

Stomach cancer

Rates (1999-2003)

In men, the incidence rates (per 100,000) of stomach cancer ranged from 11.7 in NHW to 22.5 in PR; while in women rates ranged from 5.5 in NHW to 12.9 in NHB. NHW men and women had $48 \%(\mathrm{SIR}=0.52,95 \% \mathrm{CI}=$ $0.48,0.57)$ and $50 \%(\mathrm{SIR}=0.50,95 \% \mathrm{CI}=0.46,0.55)$ lower risk, respectively, of stomach cancer, than their counterparts in PR (Table 1). No significant differences in stomach cancer risk were observed between USH and NHB men and women as compared to PR, except for NHB females who had a higher risk of the disease as compared to women in PR (SIR = 1.17, 95\% CI = 1.03-1.33). The mortality rates (per 100,000) from stomach cancer in men ranged from 6.8 in NHW to 17.1 in PR, and from 3.5 in NHW to 8.7 in NHB in women (Table 1). NHW and USH men and women had a lower risk of death than their Puerto Rican counterparts ( $\mathrm{p}<0.05)$; whereas, no significant differences in mortality were observed between NHB and PR ( $>$ > 0.05; Table 1). In all racial/ethnic groups, the incidence and mortality rates of stomach cancer were significantly higher among men as compared to women $(\mathrm{p}<0.05)$ (Table 1$)$.

\section{Trends}

From 1992-2003, the incidence of stomach cancer decreased $2 \%-3 \%$ per year in men and women from most racial/ethnic groups, except for USH and NHB women who showed relatively constant trends (Figure 1). Meanwhile, mortality showed a significantly decreasing trend for women from all racial/ethnic groups (APC between 2$4 \%$ for all groups) and a constant trend for men (Figure 2).

\section{Liver cancer \\ Rates (1999-2003)}

The incidence rates (per 100,000) of liver cancer in men ranged from 7.0 in NHW to 14.2 in USH; and in women from 3.0 in NHW to 6.4 in USH (Table 1). USH men had a $20 \%(\mathrm{SIR}=1.20,95 \% \mathrm{CI}=1.05,1.37)$ higher risk of liver cancer than men in PR. Whereas, NHW men and women had $41 \%$ and $50 \%$ lower risk of liver cancer than PR men and women, respectively. No significant differences $(\mathrm{p} \geq$ $0.05)$ in incidence rates were observed between NHB and PR men; although NHB women showed a $29 \%$ (SIR = $0.71,95 \% \mathrm{CI}=0.59,0.85$ ) lower risk of liver cancer than PR women. Mortality rates (per 100,000) from liver cancer in men ranged from 6.9 in NHW to 13.6 in PR; and in women from 3.3 in NHW to 7.8 in PR (Table 1). NHW, USH and NHB men and women had significant lower risks of death from liver cancer than men and women in $\mathrm{PR}$, ranging from $14 \%$ to $58 \%(\mathrm{p}<0.05)$ reduction in risk. In all racial/ethnic groups, both the incidence and mortality rates of liver cancer were significantly higher among men as compared to women (Table 1).

Trends (1992-2003)

Although constant incidence trends $(\mathrm{p}>0.05)$ were observed in men and women in PR and in most of the other racial/ethnic groups, the incidence trends of liver cancer showed significant increases among NHW men $(\mathrm{APC}=2.0 \%)$, NHB men $(4.9 \%)$ and NHW women (APC $=2.1 \%$ ) (Figure 1 and Figure 2). With respect to mortality, the rates showed relatively constant trends $(p>0.05)$ for all racial/ethnic groups, except for NHW women who experienced an increasing mortality trend from liver can$\operatorname{cer}(\mathrm{APC}=0.9 \%)$.

\section{Cervical cancer \\ Rates (1999-2003)}

The incidence rates (per 100,000) of cervical cancer ranged from 5.9 in NHW women to 12.7 in USH women. Although no significant differences in cervical cancer occurrence were observed between NHB and women in $\mathrm{PR}$, USH women had 40\% $(\mathrm{SIR}=1.40,95 \% \mathrm{CI}=1.28$, 1.53) higher risk of cervical cancer than women in $P R$ (Table 1). Whereas, NHW women had 35\% lower risk of cervical cancer than women in PR $(\mathrm{SIR}=0.65,95 \% \mathrm{CI}=$ $0.60,0.70$ ). Mortality rates (per 100,000) of cervical cancer ranged from 2.1 in NHW women to 5.1 in NHB women. No significant differences in mortality from cervical cancer were observed between women in PR and NHW. Whereas, USH women had a $41 \%$ and NHB women had a 2-fold significant higher risk of death from cervical cancer than women in PR $(\mathrm{p}<0.05$, Table 1$)$. 
Table 1: ASR(World) for incidence and mortality (per 100,000) for stomach, liver and cervical cancer during $1998-2003$.

\begin{tabular}{llllllll}
\hline \multicolumn{4}{c}{ Age Standardized Rate (ASR) } & & \multicolumn{2}{c}{ Standardized Relative Ratio SRR (95\% Cl) } \\
\hline PR & NHW & USH & NHB & NHW/PR & USH/PR & NHB/PR \\
\hline
\end{tabular}

\section{Incidence}

\begin{tabular}{|c|c|c|c|c|c|c|c|}
\hline Stomach & & & & & & & \\
\hline Male & 22.53 & 11.71 & 20.13 & 20.22 & $0.52(0.48-0.57)$ & $0.89(0.79-1.01)$ & $0.90(0.79-1.01)$ \\
\hline Females & 11.00 & 5.51 & 12.51 & 12.86 & $0.50(0.46-0.55)$ & $1.14(1.00-1.29)$ & $1.17(1.03-1.33)$ \\
\hline SRR Ma vs $F^{b}$ & $2.05(1.82-2.30)$ & $2.13(2.02-2.25)$ & $1.61(1.42-1.83)$ & $1.57(1.38-1.76)$ & & & \\
\hline \multicolumn{8}{|l|}{ Liver } \\
\hline Male & 11.89 & 6.96 & 14.23 & 12.20 & $0.59(0.53-0.65)$ & $1.20(1.05-1.37)$ & $1.03(0.89-1.18)$ \\
\hline Females & 5.94 & 2.95 & 6.40 & 4.21 & $0.50(0.44-0.57)$ & $1.08(0.91-1.27)$ & $0.71(0.59-0.85)$ \\
\hline SRR Ma vs Fb & $2.00(1.72-2.33)$ & $2.44(2.27-2.61)$ & $2.22(1.92-2.59)$ & $2.92(2.46-3.27)$ & & & \\
\hline \multicolumn{8}{|l|}{ Cervix } \\
\hline Females & 9.07 & 5.90 & 12.68 & 10.01 & $0.65(0.60-0.70)$ & $1.40(1.28-1.53)$ & $1.10(0.99-1.23)$ \\
\hline
\end{tabular}

\section{Mortality}

\begin{tabular}{|c|c|c|c|c|c|c|c|}
\hline Stomach & & & & & & & \\
\hline Male & 17.07 & 6.75 & 11.76 & 16.01 & $0.40(0.36-0.43)$ & $0.69(0.62-0.77)$ & $0.94(0.85-1.04)$ \\
\hline Female & 8.02 & 3.51 & 6.70 & 8.70 & $0.44(0.39-0.49)$ & $0.84(0.74-0.94)$ & $1.08(0.97-1.22)$ \\
\hline SRR Ma vs Fb & $2.13(1.85-2.45)$ & $1.92(1.88-1.97)$ & $1.76(1.62-1.90)$ & $1.84(1.75-1.92)$ & & & \\
\hline \multicolumn{8}{|l|}{ Liver } \\
\hline Male & 13.59 & 6.86 & 11.73 & 9.88 & $0.50(0.46-0.55)$ & $0.86(0.78-0.96)$ & $0.73(0.66-0.80)$ \\
\hline Females & 7.82 & 3.31 & 6.46 & 4.68 & $0.42(0.38-0.47)$ & $0.83(0.73-0.93)$ & $0.60(0.53-0.67)$ \\
\hline SRR Ma vs Fb & $1.73(1.51-1.99)$ & $2.07(2.03-2.12)$ & $1.81(1.68-1.96)$ & $2.12(1.99-2.22)$ & & & \\
\hline \multicolumn{8}{|l|}{ Cervix } \\
\hline Female & 2.38 & 2.11 & 3.36 & 5.12 & $0.89(0.76-1.04)$ & $1.41(1.20-1.68)$ & $2.16(1.84-2.55)$ \\
\hline
\end{tabular}




\section{Trends (1992-2003)}

Significant decreases in the incidence trends of cervical cancer were observed for women from all racial/ethnic groups from 1992-2003, ranging from -2.2 for PR to $-4.2 \%$ for USH. Similarly, significant decreases in cervical cancer mortality were also observed for all groups, except for PR where the decline was non-significant ( $\mathrm{p}>0.05)$ (Figure 2).

\section{Discussion}

Our study adds updated information to the previous knowledge on infection-related cancers in PR as compared to specific racial/ethnic groups in the US $[7,10,11]$. The higher incidence and mortality rates of stomach, liver and cervical cancer observed among PR, NHB and USH as compared to NHW are consistent with previous studies in these populations $[7,10,11,14]$. Given the infectious etiology of these cancers, these results might suggest a higher prevalence of certain infectious agents among these populations, and of the risk factors associated with these infections and neoplastic conditions.

\section{Liver Cancer}

\section{Rates}

Disparities in incidence rates of liver cancer among the studied racial/ethnic groups are likely the result of variations in the distribution of risk factors in these populations, such HCV/HBV infection, genetics and environmental factors or $\mathrm{HBV}$ vaccination coverage $[27,28]$. The higher risk of liver cancer in men as compared to women in PR and racial/ethnic groups studied is consistent with previous data for PR $[29,30]$ and the US [14]. This has been explained by higher prevalence of risk factors for liver cancer in men as compared to women $[31,32]$, such as higher alcohol consumption and HBV/ $\mathrm{HCV}$ infection [33-35]. In the US, the prevalence of $\mathrm{HCV}$ in the general population ranges from $1.5 \%$ in NHW, $3.0 \%$ in NHB [19] and 2.3\% in PR [34]. Similarly, the prevalence of HBV infection has also been shown to be greater for NHB than for NHW [36]. Although data on HBV and $\mathrm{HCV}$ for the USH population is scarce and may not accurately reflect the true proportion of people infected [33]; a higher prevalence of $\mathrm{HBV}$ in the majority of Latin American countries than in the US has been documented [37], but data for HCV is very limited [38]. Although a higher incidence of both $\mathrm{HCV}$ and/or $\mathrm{HBV}$ infection among USH and PR than among NHW is difficult to document, high risk behaviors for HCV infection, such as drug use and needle-sharing are high in PR and among $\mathrm{NHB}$ and USH $[39,40]$. In addition, lower HBV vaccination coverage has been documented for NHB and USH children and adults in the US $[27,28,34]$. Finally, of special interest are the significantly higher mortality rates from liver cancer among men and women in PR compared to
USH, NHW and NHB. This result highlights health disparities between the study groups, probably explained by higher exposure to $\mathrm{HCV} / \mathrm{HBV}$, more advanced stage at disease diagnosis, decreased access to effective therapies and overall access to care in PR that warrants further attention and research.

\section{Trends}

Our study showed relatively constant trends in the incidence and mortality from liver cancer in PR, USH and NHB; however, incidence trends among NHB men increased. Increasing incidence and mortality patterns were also observed among NHW men and women, a result consistent with other studies in the US [41]. A possible explanation for the rising incidence of liver cancer among NHW and NHB men is an increase in the prevalence of cirrhosis, mostly secondary to chronic infection with $\mathrm{HCV}[41,42]$. Also, the $\mathrm{HCV}$ cohort of patients infected by intravenous drug use during the 1960's-1980 has been responsible for the increasing incidence trends of liver cancer in the US $[41,42]$. In PR, despite the constant trends in the incidence of liver cancer, it is expected to increase in the next decades as a result of the projected higher prevalence of HCV-related cirrhosis [42]. Meanwhile, the constant mortality trend in most study groups suggests that no major advances in prevention and/or treatment of liver cancer have been achieved. For example, no treatment has been proven effective in preventing progression to chronic liver disease and HCC among HBV carriers [6].

\section{Stomach Cancer \\ Rates}

The higher incidence of stomach cancer in PR compared to NHW (although similar to that of NHB and USH) suggests a higher prevalence of stomach cancer risk factors in this population, including $H$. pylori infection as well as other factors associated with infection, or other known risk factors for stomach cancer such as a high intake of salty foods and/or N-nitroso compounds [43-45]. Although data on the prevalence of $H$. pylori is scarce in $\mathrm{PR}$, infection rates with $H$. pylori are higher in NHB (52.7\%) and USH (61.6\%) populations as compared to NHW (26.3\%) in the US [45]. This pattern supports the higher incidence rates from stomach cancer among Hispanic populations in the US, similar to Latin American countries $[2,10,13]$. These results suggest a higher burden of $H$. pylori infection in PR, USH and NHB than in NHW, thus, additional data in PR is warranted. Meanwhile, the higher risk of stomach cancer in men as compared to women in PR and in all racial/ethnic groups studied is consistent with data for PR $[29,30]$ and the US [14]. This difference is explained by a higher prevalence of risk factors for this cancer in men as compared to women [31,32], such as H. pylori infection [33-35]. Mortality 

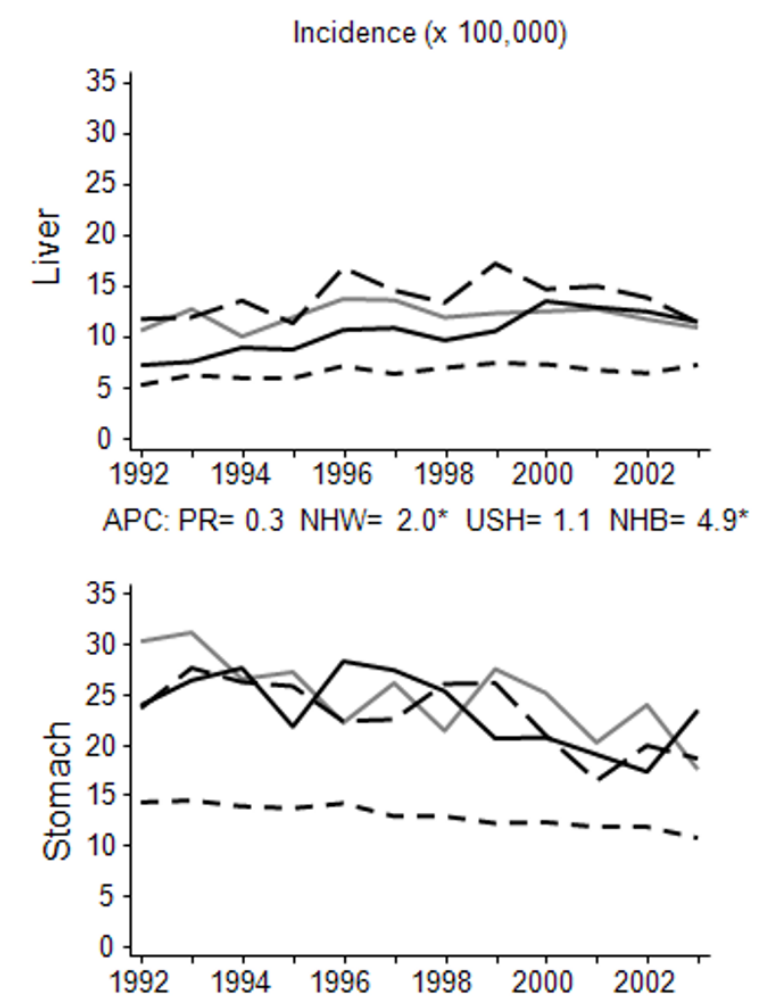

APC: $\mathrm{PR}=-3.4^{\star} \mathrm{NHW}=-2.5^{\star} \mathrm{USH}=-3.0^{\star} \mathrm{NHB}=-2.9^{\star}$
Mortality (x 100,000)
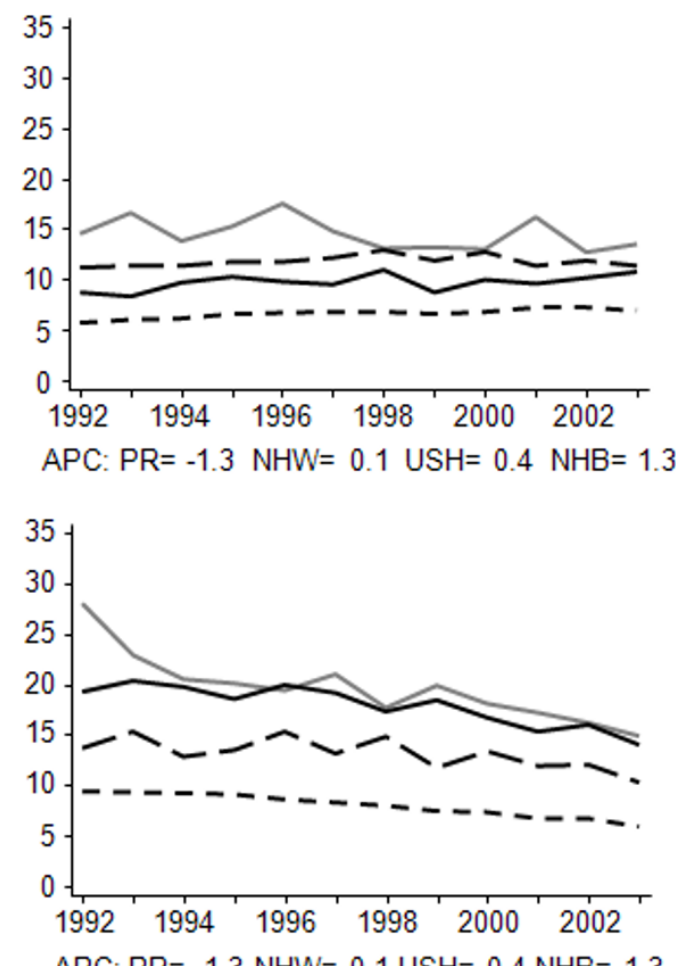

APC: $P R=-1.3 \mathrm{NHW}=0.1 \mathrm{USH}=0.4 \mathrm{NHB}=1.3$

Legend: PR $\longrightarrow \mathrm{NHW}----\mathrm{USH}--\mathrm{NHB}$

${ }^{*}$ Statistically significant $(p<0.05)$

Figure 1 Trends for stomach and liver cancer among men in all racial/ethnic groups, 1992-2003.

rates from stomach cancer were also significantly higher for men and women in PR than for USH and NHW (although similar to NHB). These differences might be explained by differences in stage of disease at diagnosis, decreased access to effective therapies and overall access to care in PR and among NHB. These differences warrant further attention and research. Among prevention strategies, early eradication of $H$. pylori infection in high risk patients (such as those of patients with peptic ulcer disease) should be promoted in PR, as this reduces gastric cancer risk by reversing many biochemical, genetic and epigenetic changes in stomach cancer induced by $H$. pylori infection [46].

\section{Trends}

Decreasing incidence trends from stomach cancer observed in our study are consistent to patterns observed worldwide [6]. Although the reasons for these declines are not well understood, they are thought to be related to improvements in diet, food storage, as well as a reduction in the prevalence of $H$. pylori infection caused by increasing levels of living standards over the past 50 years and an increased use of antibiotics $[6,47,48]$. The same could be hypothesized for PR, given the improvements in living conditions, education and sanitation [49]. In addition to these factors, decreasing mortality trends may also be explained by increased access to care in all population sub-groups.

\section{Cervical Cancer \\ Rates}

The higher incidence of cervical cancer observed among USH, NHB and PR could reflect a potential higher prevalence of HPV infection in these populations or lower screening rates in these groups. Although no populationbased data for the prevalence of HPV have been reported in PR that might explain the burden of cervical cancer among women in this population, a high incidence of cervical cancer has been observed in developing Latin American countries $(33.5$ per 100,000$)$ and the Caribbean (33.5 per 100,000) [50]. Although studies in the 1990's suggested a higher prevalence of HPV in USH and NHB in the US as compared to NHW [51], which support the 

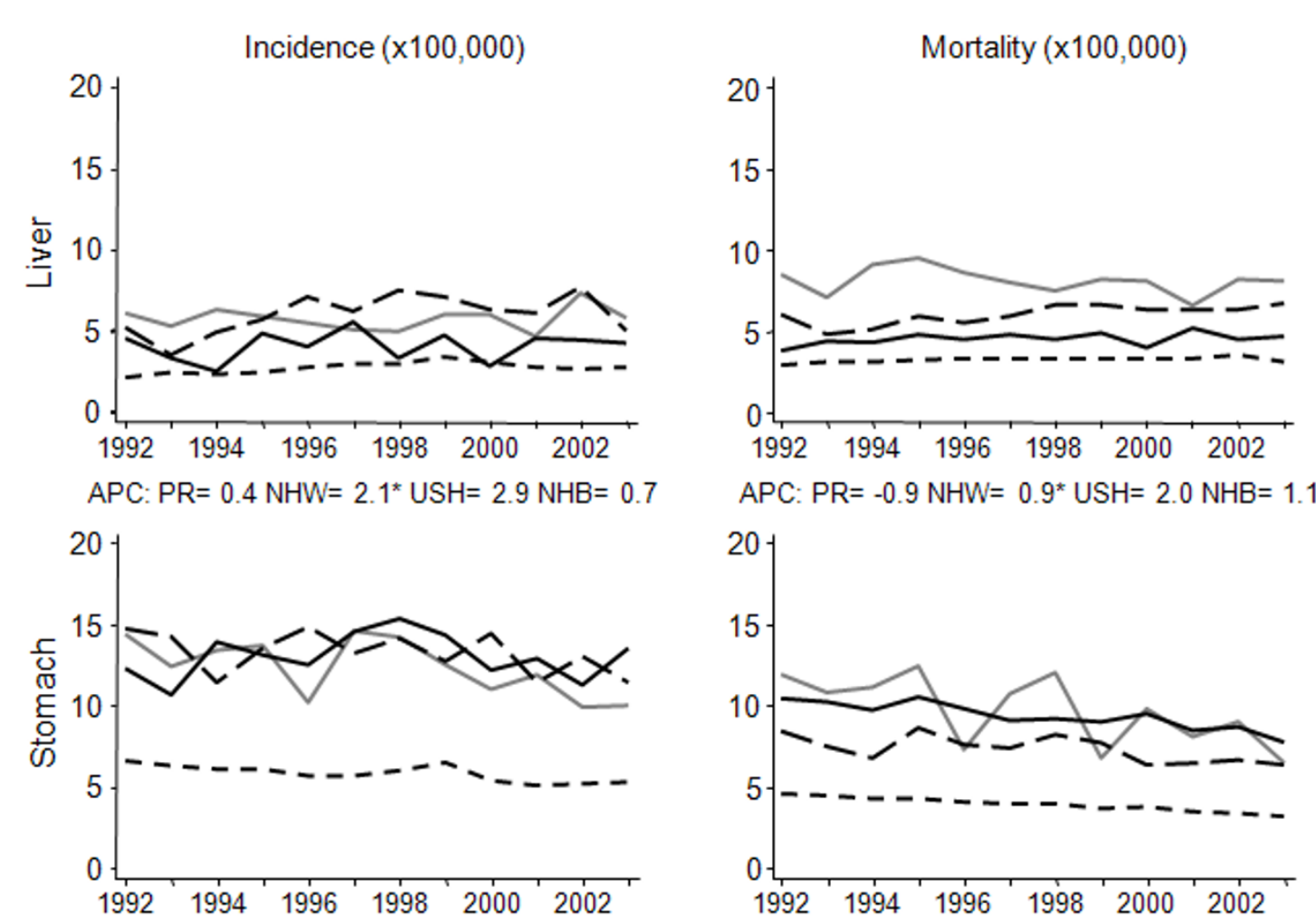

APC: $P R=-2.5^{\star} \mathrm{NHW}=-1.9^{\star} \mathrm{USH}=-1.3 \mathrm{NHB}=0.4$

APC: $P R=-3.8^{*} \mathrm{NHW}=-3.0^{*} \mathrm{USH}=-2.0^{*} \mathrm{NHB}:-2.1^{*}$
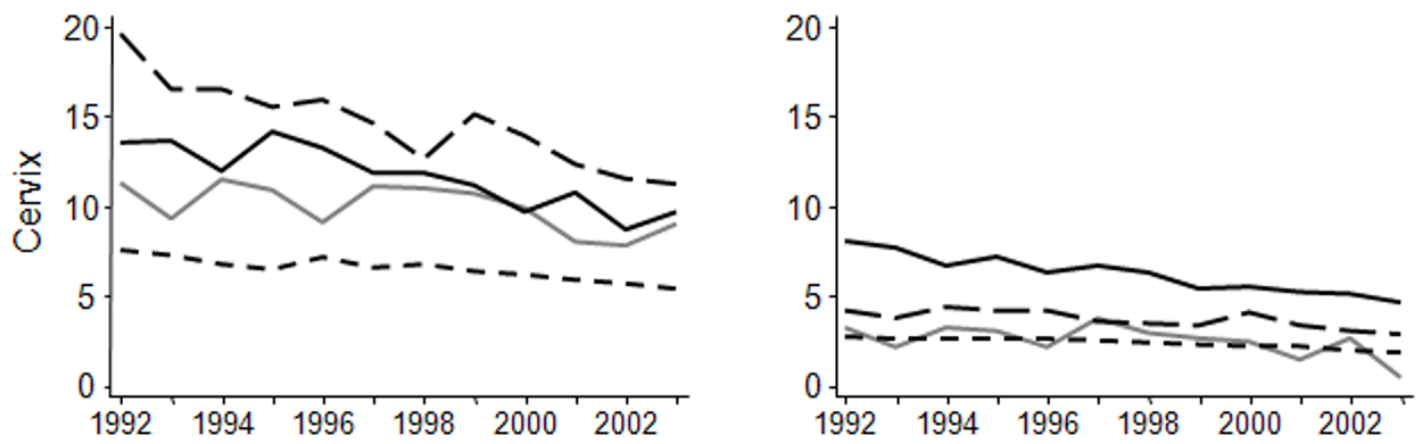

APC: $\mathrm{PR}=-2.2^{\star} \mathrm{NHW}=-2.6^{\star} \mathrm{USH}=-4.2^{\star} \mathrm{NHB}=-3.7^{\star} \quad$ APC: $\mathrm{PR}=-4.0 \mathrm{NHW}=-2.9^{\star} \mathrm{USH}=-2.8^{\star} \mathrm{NHB}=-3.7^{\star}$

Legend: $\mathrm{PR} \longrightarrow \mathrm{NHW}----\mathrm{USH}--\longrightarrow \mathrm{NHB}-$

* Statistically significant $(p<0.05)$

Figure 2 Trends for stomach, liver and cervical cancer among women in all racial/ethnic groups, 1992-2003

higher burden of cervical cancer in these groups, more recent studies show a higher prevalence among NHB but not among USH [52]. The higher incidence of cervical cancer in these groups may also be influenced by the high HIV/AIDS burden in these minority populations [53,54], as cervical cancer is an important AIDS-defining illness and may be the most common AIDS-related malignancy in women [55]. Regarding mortality, PR and NHW had similar risks of death from this malignancy, while USH and NHB had increased risk. Disparities in cervical can- cer screening compliance between these racial/ethnic groups could also account for some of the observed differences in both incidence and mortality. Nonetheless, the lower prevalence of cervical cancer screening in PR (70.2\% in $1996,73.3 \%$ in 2002$)$ than in the US $(84.7 \%$ in $1996,87.2 \%$ in 2002) $[35,56]$ and to those of the studied racial/ethnic groups (>85\%) does not support the lower mortality from the disease in PR as compared to NHB and USH. 


\section{Trends}

Decreasing patterns of cervical cancer incidence and mortality are consistent with data in PR [57] and the US [58] and supported by the increased use of cervical cancer screening in these populations. Although they could also be influenced by decreasing patterns of HPV infection in these populations, historical data of HPV infection to support this hypothesis is unavailable. Nonetheless, this is less likely given that infection with HPV is associated with high risk sexual practices, such as, early age of sexual intercourse, multiple sex partners, and lifetime number of partners; and in fact, high risk sexual practices that have increased in younger cohorts [59].

\section{Strengths and Limitations}

This study provides updated population-based data on the burden of infections-related cancers in PR compared to racial/ethnic groups in the US. Among study limitations, incomplete information regarding stage at diagnosis of cancer cases in PR limits our ability to consider the impact of staging on cancer trends. Also, even though PR is a Hispanic population, Hispanics in the US constitute a heterogeneous group of persons from a variety of Hispanic origins that show substantial variability in cancer rates [11]. Even though the Hispanic population residing in the US described in our study is not directly comparable to the Puerto Rican population living in PR, racial/ ethnic group comparisons identify disparities in the burden of disease and generate hypotheses about the role of environmental, genetic, social, and lifestyle factors on cancer occurrence $[7,60,61]$.

\section{Conclusions}

In conclusion, the higher overall burden of liver, stomach and cervical cancer among PR, USH and NHB, as compared to NHW, shows a health disparity between these groups that could be explained by various factors: 1) higher prevalence of infection with oncogenic infectious agents in these racial/ethnic populations, 2) lower rates of appropriate screening and early detection of cancer in these groups, and 3) differences in access to advances in preventive and treatment options among these populations. Nonetheless, the declining trends in the incidence and mortality of stomach and cervical cancer in PR might be explained by improvements in socioeconomic status, reductions in the burden of infectious agents and improvements in access to preventive and treatment care. Further research is warranted to understand the observed differences in cancer occurrence across these populations, with a particular focus on the burden of cancerrelated infectious agents in these populations and the factors associated with disease progression.
Competing interests

The authors declare that they have no competing interests.

\section{Authors' contributions}

APO conceived the study, participated in its design and coordination and wrote the manuscript. MSS and WAC performed the statistical analysis and helped to draft the manuscript. GTL, CMP and CR helped to draft the manuscript. JP and NF provided the data and helped to draft the manuscript. ES supported the conception of the study, participated in its design and coordination and helped to draft the manuscript. All authors read and approved the final manuscript.

\section{Acknowledgements}

This work was supported by the Puerto Rico Cancer Center/The University of Texas M. D. Anderson Cancer Center, Partners for Excellence in Cancer Research [Grant \#U54CA96297] and the Training in Computational Genomic Epidemiology of Cancer [Grant\# 5R25CA094186-08]; the Research Centers in Minority Institutions Program [Grant \#G12RR03051] from the University of Puerto Rico; and by the Centers for Disease Control and Prevention-National Program Cancer Registries [Grant \#U58DP000782-01] for the Puerto Rico Central Cancer Registry.

\section{Author Details}

${ }^{1}$ Cancer Control and Population Sciences Program, University of Puerto Rico Comprehensive Cancer Center, San Juan, Puerto Rico, ${ }^{2}$ Graduate School of Public Health, Department of Biostatistics and Epidemiology, Medical Sciences Campus, University of Puerto Rico, San Juan, Puerto Rico, ${ }^{3}$ Medical Sciences Campus, Puerto Rico Cancer Center, University of Puerto Rico, San Juan, Puerto Rico, ${ }^{4}$ School of Medicine, Gastroenterology Research Unit, Medical Sciences Campus, University of Puerto Rico, San Juan, Puerto Rico and ${ }^{5}$ Puerto Rico Central Cancer Registry, San Juan, Puerto Rico

Received: 30 June 2009 Accepted: 14 May 2010

Published: 14 May 2010

References

1. De Martel C, Franceschi S: Infections and cancer: established associations and new hypotheses. Crit Rev Oncol Hematol 2009 70:183-94.

2. Mackay J, Jemal A, Lee N, Maxwell-Parkin D: The Cancer Atlas. American Cancer Society 2006

3. Parkin DM: The global health burden of infection-associated cancers in the year 2002. Int J Cancer 2006, 118:3030-3044.

4. Grulich $A E$, Vajdic CM: The epidemiology of non-Hodgkin lymphoma. Pathology 2005, 37:409-19.

5. Grulich E: AIDS-associated non-Hodgkin's lymphoma in the era of highly active antiretroviral therapy. J Acquir Immune Defic Syndr 1999, 21(Suppl 1):S27-30.

6. Thun MJ, DeLancey JO, Center MM, Jemal A, Ward EM: The global burden of cancer: Priorities for prevention. Carcinogenesis 2010, 31:100-10.

7. Martinez I, Torres R, Frias Z: Cancer incidence in the United States and Puerto Rico. Cancer Res 1975, 35:3265-3271.

8. All Sites Cancer Stat Fact Sheet [http://www.salud.gov.pr/RCancer/ Reports/Pages/default.aspx]. Puerto Rico Central Cancer Registry, San Juan, PR

9. American Cancer Society: Cancer Facts \& Figures 20082006 [http:// www.cancer.org/downloads/STT/2008CAFFfinalsecured.pdf. Atlanta, GA: American Cancer Society

10. Ho GY, Figueroa-Vallés NR, De La Torre-Feliciano T, Tucker KL, TortoleroLuna G, Rivera WT, Jiménez-Velázquez IZ, Ortiz-Martínez AP, Rohan TE: Cancer disparities between mainland and island Puerto Ricans. Rev Panama Salud Publica 2009, 25:394-400.

11. Pinheiro PS, Sherman RL, Trapido EJ, Fleming LE, Huang Y, Gomez-Marin O, Lee D: Cancer incidence in first generation U.S. Hispanics: Cubans, Mexicans, Puerto Ricans, and new Latinos. Cancer Epidemiol Biomarkers Prev 2009, 18:2162-9.

12. Top Ten Cancer Sites and Deaths [http://www.Salud.gov.pr/RCancer/ Reports/Pages/default.aspx]. Puerto Rico Central Cancer Registry, San Juan, PR 
13. Canto MT, Chu KC: Annual cancer incidence rates for Hispanics in the United States: Surveillance, epidemiology, and end results, 1992-1996. Cancer 2000, 88:2642-52.

14. Carozza S, Howe H: Patterns of cancer incidence among US Hispanics/ Latinos, 1995-2000. Cancer Causes Control 2006, 17:1067-1075.

15. O'Brien K, Cokkinides V, Jemal A, Cardinez CJ, Murray T, Samuels A, Ward E, Thun MJ: Cancer statistics for Hispanics, 2003. CA Cancer J Clin 2003, 53:208-226

16. Abraído-Lanza AF, Chao MT, Flórez KR: Do healthy behaviors decline with greater acculturation? Implications for the Latino mortality paradox. Soc Sci Med 2005, 61:1243-1255.

17. Puerto Rico Central Cancer Registry: Puerto Rico Cancer Incidence File (January 2008). Division of Epidemiology, Puerto Rico Department of Health, San Juan, Puerto Rico.

18. Puerto Rico Central Cancer Registry: Puerto Rico Mortality File (August 2006). Division of Statistical Analysis, Auxiliary Secretarial for Planning and Development, Puerto Rico Department of Health, San Juan, Puerto Rico.

19. Surveillance, Epidemiology, and End Results (SEER) Program: SEER*Stat Database: Incidence - SEER 13 Regs Limited-Use, Nov 2006 Sub (1992 2004) - Linked To County Attributes - Total U.S., 1969-2004 Counties, National Cancer Institute, DCCPS, Surveillance Research Program, Cancer Statistics Branch, released April 2007, based on the November 2006 submission.

20. Surveillance, Epidemiology, and End Results (SEER) Program.: SEER*Stat Database: Mortality - All COD, Aggregated With State, Total U.S. (19902004), National Cancer Institute, DCCPS, Surveillance Research Program, Cancer Statistics Branch, released April 2007. Underlying mortality data provided by NCHS.

21. Martínez I: Experiencia en el Registro de Cáncer en Puerto Rico. Bol Asoc Med PR 1991, 83:258-260

22. ORC MacroSM: National Program of Cancer Registries, Technical Assistance and Audit Puerto Rico Central Cancer Registry 2000, Case Completeness and Data Quality Audit. Centers for Disease Control and Prevention. Department of Health and Human Services; 2003:1-32.

23. Waller LA, Gotway CA: Applied spatial statistics for public health data Hoboken, New Jersey: John Wiley \& Sons, Inc; 2004

24. Kim HJ, Fay MP, Feuer EJ, Midthune DN: Permutation tests for joinpoint regression with applications to cancer rates. Stat Med 2000, 19:335-351.

25. Joinpoint Regression Program, Version 3.3 - April 2008. Statistical Research and Applications Branch National Cancer Institute.

26. Tiwary RC, Clegg LX, Zou Z: Efficient interval estimation for ageadjusted cancer rates. Stat Methods Med Res 2006, 15:547-569.

27. Centers for Disease Control and Prevention (CDC): Hepatitis B Vaccination Coverage among Adults-United States, 2004. MMWR 2006, 55:509-511.

28. Yusuf $H$, Daniels $D$, Mast EE, Coronado V: Hepatitis B vaccination coverage among United States children. Pediatr Infect Dis J 2001, 20:S30-3.

29. Cancer of the Liver and Intrahepatic Bile Duct Stat Fact Sheet [http:// www.salud.gov.pr/RCancer/Reports/Pages/default.aspx]. Puerto Rico Central Cancer Registry, San Juan, PR

30. Cancer of the Stomach Stat Fact Sheet [http://www.salud.gov.pr/ RCancer/Reports/Pages/default.aspx]. Puerto Rico Central Cancer Registry, San Juan, PR

31. Nomura A: Stomach Cancer. In Cancer Epidemiology and Prevention Edited by: Schottenfeld D, Fraumeni JF. Oxford University Press; 1996:707-721.

32. London WT, McGlynn KA: Liver cancer. In Cancer Epidemiology and Prevention Edited by: Schottenfeld D, Fraumeni JF. Oxford University Press; 1996:772-785

33. Armstrong G, Wasley A, Simard E, McQuillan GM, Kuhnert WL, Alter M The prevalence of hepatitis C virus infection in the United States, 1999 through 2002. Ann Intern Med 2006, 144:705-714.

34. Perez CM, Marrero E, Meléndez M, Adrovet S, Colón H, Ortiz AP, SotoSalgado M, Albizu C, Torres E, Suárez E: Seroepidemiology of viral hepatitis, HIV and herpes simplex type 2 in the household population aged 21-64 years in Puerto Rico. BMC Infectious Diseases 2010, 10:

35. Hughes E, McCracken M, Roberts H, Mokdad AH, Valluru B, Goodson R, Dunn E, Elam-Evans L, Giles W, Jiles R: Surveillance for certain health behaviors among states and selected local areas--Behavioral Risk Factor Surveillance System, 2004. MMWR Surveill Summ 2006, 55:1-124.
36. McQuillan GM, Coleman PJ, Kruszon-Moran D, Moyer LA, Lambert SB, Margolis HS: Prevalence of hepatitis B virus infection in the United States: The National Health and Nutrition Examination Surveys, 1976 through 1994. Am J Public Health 1999, 89:14-8.

37. Tanaka J: Hepatitis B epidemiology in Latin America. Vaccine 2000 18(Suppl 1):S17-19.

38. Soza A, López-Lastra M: Hepatitis C in Chile: Burden of the disease. Rev Med Chil 2006, 134:777-788.

39. Deren S, Robles R, Andia J, Colón HM, Kang SY, Perlis T: Trends in HIV seroprevalence and needle sharing among Puerto Rican drug injectors in Puerto Rico and New York: 1992-1999. J Acquir Immune Defic Syndr 2001, 26:164-169.

40. Cooper HL, Brady JE, Friedman SR, Tempalski B, Gostnell K, Flom PL: Estimating the prevalence of injection drug use among black and white adults in large U.S. metropolitan areas over time (1992--2002): Estimation methods and prevalence trends. J Urban Health 2008, 85:826-56.

41. El-Serag HB, Mason AC: Rising incidence of hepatocelullar carcinoma in the United States. N Eng/ J Med 1999, 340:745-750

42. Romero C, Ortiz AP, Perez C, Perez J, Torres E: Survival of hepatocellular carcinoma in Puerto Rico. P R Health Sci J 2009, 28:105-13.

43. Nomura A, Stemmermann GN, Chyou PH, Kato I, Perez-Perez GI, Blaser MJ: Helicobacter pylori infection and gastric carcinoma among Japanese Americans in Hawaii. NEngl J Med 1991, 325:1132-1136.

44. Nazario CM, Szklo M, Diamond E, Román-Franco A, Climent C, Suarez E, Conde JG: Salt and gastric cancer: A case-control study in Puerto Rico. Int J Epidemiol 1993, 22:790-7.

45. Everhart JF, Kruszon-Moran D, Perez-Perez GI, Tralka TS, Maquillan G: Seroprevalence and ethnic differences in Helicobacter pylori infection among adults in the United Sates. J Infect Dis 2000, 181:1359-1363.

46. Kabir S: Effect of Helicobacter pylori eradication on incidence of gastric cancer in human and animal models: Underlying biochemical and molecular events. Helicobacter 2009, 14:159-71.

47. Crew K, Neugut A: Epidemiology of gastric cancer. World J Gastroenterol 2006, 12:354-362

48. Blaser MJ: Hypothesis: The changing relationships of Helicobacter pylori and humans: Implications for health and disease. $J$ Infect Dis 1999, 179(6):1523-30.

49. Rigau-Pérez J: La Salud en Puerto Rico en el Siglo XX. P R Health Sci J 2000, 19:357-368.

50. Parkin DM, Bray F: Chapter 2: The Burden of HPV-related cancers. Vaccine 2006, 24(Suppl 3):11-25.

51. Burk RD, Ho GY, Beardsley L, Lempa M, Peters M, Bierman R: Sexual behavior and partner characteristics are the predominant risk factors for genital human papilloma virus infection in young women. J Infect Dis 1996, 174:679-689.

52. Dunne EF, Unger ER, Sternberg M, McQuillan G, Swan DC, Patel SS, Markowitz LE: Prevalence of HPV infection among females in the United States. JAMA 2007, 297:813-819.

53. Hall HI, Geduld J, Boulos D, Rhodes P, An Q, Mastro TD, Janssen RS, Archibald CP: Epidemiology of HIV in the United States and Canada: Current status and ongoing challenges. J Acquir Immune Defic Syndr 2009, 51(Suppl 1):S13-20.

54. Miranda S, Lopez B, García-Rivera EJ, Rangel M, Hernandez AL, Espinoza L, Myles Z: Incidence and diagnoses of HIV infection, Puerto Rico, 2006. MMWR 2009, 58:589-591.

55. Maiman M, Fruchter RG, Clark M, Arrastia CD, Matthews R, Gates EJ: Cervical cancer as an AIDS-defining illness. Obstet Gynecol 1997, 89(1):76-80

56. Holtzman D, Powell-Griner E, Bolen JC, Rhodes L: State and sex-specific prevalence of selected characteristics-Behavioral Risk Factor Surveillance System, 1996 and 1997. MMWR CDC Surveill Summ 2000, 49:1-39.

57. Cancer of Cervix Uteri Stat Fact Sheet [http://www.salud.gov.pr/ RCancer/Reports/Pages/default.aspx]. Puerto Rico Central Cancer Registry, San Juan, PR

58. Edwards BK, Brown ML, Wingo PA, Howe HL, Ward E, Ries LA, Schrag D, Jamison PM, Jemal A, Wu XC, Friedman C, Harlan L, Warren J, Anderson RN, Pickle LW: Annual report to the nation on the status of cancer, 19752002 , featuring population-based trends in cancer treatment. J Natl Cancer Inst 2005, 97:1407-1407. 
59. Finer $L B$, Darroch JE, Singh $\mathrm{S}$ : Sexual partnership patterns as a behavioral risk factor for sexually transmitted diseases. Family Planning Perspectives 1999, 31:228-236.

60. Suárez E, Calo WA, Hernandez EY, Diaz EC, Figueroa NR, Ortiz AP: Agestandardized incidence and mortality rates of oral and pharyngeal cancer in Puerto Rico and among Non-Hispanics Whites, Non-Hispanic Blacks, and Hispanics in the USA. BMC Cancer 2009, 28:129.

61. Tang H, Choudhry S, Mei R, Morgan M, Rodriguez-Cintron W, Burchard EG, Risch NJ: Recent genetic selection in the ancestral admixture of Puerto Ricans. Am J Hum Genet 2007, 81:626-633.

doi: $10.1186 / 1750-9378-5-10$

Cite this article as: Ortiz et al., Incidence and mortality rates of selected infection-related cancers in Puerto Rico and in the United States Infectious Agents and Cancer 2010, 5:10

Submit your next manuscript to BioMed Central and take full advantage of:

- Convenient online submission

- Thorough peer review

- No space constraints or color figure charges

- Immediate publication on acceptance

- Inclusion in PubMed, CAS, Scopus and Google Scholar

- Research which is freely available for redistribution

Submit your manuscript at www.biomedcentral.com/submit
C) Biomed Central 